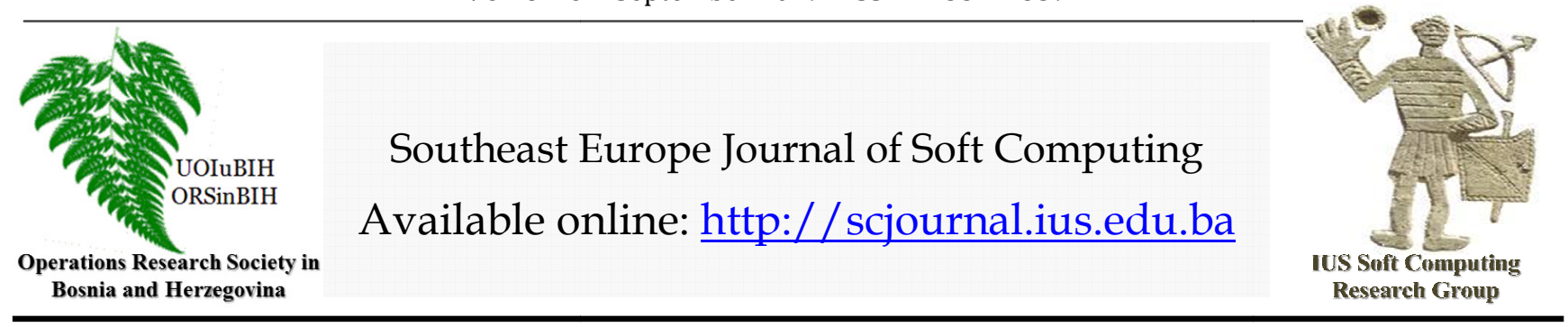

\title{
Type-2 Fuzzy TOPSIS Model For Green Third Party Logistics Provider Performance Evaluation
}

C. Atasever ${ }^{1 *}$,

B. Ayvaz ${ }^{2}$

Faculty of Engineering and Design,

Istanbul Commerce University, Institute of Science, Industrial Engineering

Istanbul, Turkey

atasever_crn@hotmail.com

bayvaz@ticaret.edu.tr

\section{Article Info}

Article history:

Article received on Septenber 122019

Received in revised form October 222019

Keywords:

Fuzzy Set Theory, Multi-Criteria Decision

Making, Green Supplier Evaluation, İnterval

Type-2 Fuzzy TOPSIS

\begin{abstract}
Green supplier selection, along with the environmental dimension in the supply chain, has attracted great interest both in the academic and institutional framework however, the supplier selection as well as the evaluation the performance of the current supplier affects the performance of the company and is important. In the real life, uncertainties in decision-making process are an integral part of this process. are things that exist in the nature of decisionmaking. Fuzzy set theory with the linguistic preferences was used to transform subjective decision-maker perceptions into a tangible net value. In this paper, it is proposed an interval type- 2 fuzzy TOPSIS approach for green performance evaluation in GSCM. Then, it is applied in the performance evaluation of 3rd Party Logistics (3PL) providers to validate the presented model.
\end{abstract}

\section{INTRODUCTION}

The Supply chain (SC), including all processes from the raw material to end product and recycling of a product, has a complex and multifactorial life cycle such as including purchasing, production, sales, packaging and reverse logistics in this process (Yiner et al., 2011).

For many years, focusing on supply chain management (SCM) has been seen as a strategic way to obtain competitive advantage (Khodaverdi et al., 2013) and in partically, "supplier selection problem" has been recognized as a one of the most critical decision for organizations due to its direct effect on cash flow and profitability of the company (Banaeian et al., 2018).

The more wastes are generated as a result of production activities based on the increasing population and demand. It has caused air, water and soil pollution and these pollution causes many environmental problems such as climate change, acid rain, global warming and depletion of ozone laver and threaten us. future generations and our world
(Boyacı and Çolak, 2018). The strategies such as "green principles and environmental performance have become vital for companies due to the awareness of people about the environmental problems caused by this pollution and increasing concerns for future generations and our world (Büyüközkan and Çifçi, 2012). Recent years, because of the increasing importance of the environmental consciousness the companies have taken attention environmental selection criteria in order to determine the best supplier.

A company's environmental performance is highly affected to the environmental performance of the suppliers. The awareness and environmental policies of the governments brought the novel concept of SC to a different dimension and created the concepts of "Green Supply Chain" (GSC) and "Green Supply Chain Management" (GSCM) (Büyüközkan and Çifçi, 2012).

GSCM is seen "the way of survival in the global market" which aims to minimize or to eliminate the negative impacts 
achieving the companies' profit and market share targets (Büyüközkan and Çifçi, 2012; Khodaverdi et al., 2013; Uygun and Dede, 2016). Therefore, partnerships with environmentally and economically strong suppliers has gained strategic importance and companies need to consider GSCM practices in green supplier selection process and they improve the green / environmental performance of their existing suppliers (Khodaverdi et al., 2013).

When the literature is reviewed from past to present, it is seen that there is a big gap the studies are focused on the green supplier selection (Büyüközkan et al., 2008; Kannan et al., 2014; Jharkharia and Shankar, 2007). For this reason, this study presents a new model for green / environmental performance evaluation based on the key criteria in green supplier selection. GSCM requires multi-dimensional approaches and therefore multi criteria decision making (MCDM) techniques should be applied in order to evaluate GSCM performance (Uygun and Dede, 2016).

In addition, fuzzy set theory with linguistic preferences is used to turn the perceptions of subjective decision makers into a concrete net value. When previous studies were examined, MCDM are generally used with type-1 fuzzy numbers. (Ayvaz and Kuşakç1, 2017), using type-1 and type-2 fuzzy sets (T2FS) separately in their study, seen that T2FS gave better results. Therefore, in this study, trapezoidal type-2 fuzzy TOPSIS (Order of Similarity to Ideal Solution Technique) (T2FT) method was used to create a general performance score for each alternative. The proposed method has been applied to evaluate the performance of three 3rd Party Logistics (3PL) providers operating in the logistics sector.

This paper is organized as follows. Section 2 the literature review is made. In Section 3, it is addressed the concepts of type-2 fuzzy sets andtype-2 fuzzy (T2F) TOPSİS. In Section 4 , the proposed model is applied to evaluate the Green Performance of three 3PL companies and sensitivity analysis is performed to see the results under different conditions.

\section{LITERATURE}

In this section, it is conducted a comprehensive literature review as following.

Jharkharia and Shankar (2007) used the Analytical Network Process (ANP) method under the main headings of Compatibility, Cost, Quality, Reputation for the selection of the 3PL provider. In a result of this study, the compatibility between the company and the 3PL provider it was seen to be the most important determinant for the final selection process. Yiner et al. (2011) analyzed the main factors and the relationships between them during the study of Sustainable Supply Chain (SSC) and combined them with
ANP and applied the model in a numerical example. Büyüközkan and Çifçi (2011) defined the supplier selection process as an operational task for SSC and aimed to evaluate sustainable suppliers in the model they proposed. The proposed model is fuzzy ANP. The model has applied for the supplier firms in the market. Kannan et al. (2009) proposed the type-1 fuzzy TOPSIS approach, one of the fuzzy MCDM methods, in order to select a 3rd Party Reverse Logistics Provider, arguing that the return of used products is an important logistic activity to protect the environment and reduce waste. The model was applied to select supplier for a battery manufacturing company in India.

The toevulation the environmental performance of suppliers (Awasthi et al., 2010), it has been seen proposed TOPSIS, which is one of the MCDM methods because TOPSIS can distinguish between negative and positive category criteria such as Benefit (the better the better) and Cost (the less the better) and chooses the solution that is close to the positive ideal solution and away from the negative ideal solution. Due to the linguistic variables was used, TOPSIS type- 1 is combined with fuzzy set and a numerical solution is presented.

Jayant et al. (2014) proposed AHP-TOPSIS binary approach for the selection of a 3PL provider that could provide reverse logistics services and applied the model to a mobile phone manufacturing company for the supplier selection study. Which draws attention to the incredible growth of the internet (Büyüközkan et al., 2008), emphasized the need to move from the traditional logistics service to the e-logistics system and applied the binary MCDM method in order to select an e-logistics partner. It is seen that triangular fuzzy numbers are used because subjective preferences are used. The weights of the main and sub-criteria determined in the first stage were calculated using the Fuzzy Analytic Hierarchy Process (AHP) method and in the last stage, fuzzy TOPSIS was applied to obtain the final common ranking results. Sun (2010)proposed a model in which criteria are weighted with fuzzy AHP and a solution is obtained with fuzzy TOPSIS for performance evaluation. Uysal (2012) proposed DEMATEL, one of the MCDM methods for the performance measurement of SCM, and applied it on three manufacturing companies.

Govindan et al. (2015) used fuzzy-based DEMATEL method to evaluate GSCM applications and presented a case study from the automotive industry to evaluate the effectiveness of the proposed method. The results show that "internal management support", "green purchasing" and "ISO 14001" certification are the most important GSCM applications. Büyüközkan and Çifçi (2012) used a hybrid MCDM approach based on fuzzy DEMATEL, fuzzy ANP and fuzzy TOPSIS to select green supplier for Ford Otosan. For the purpose of green supplier performance evaluation 
23 C. Atasever, and B. Ayvaz / Southeast Europe Journal of Soft Computing Vol.8 No.2 September 2019 (21-30)

(Dobos and Vörösmarty, 2014), the Common Weighting Method and Data Envelopment Analysis (DEA) binary approach was used in their studies, and the Common Weighting Method was applied for criteria weights and a solution was obtained with DEA at the last stage.

Rostamzadeh et al. (2015) proposed fuzzy VIKOR for the evaluation of GSCM applications, and applied the model for a GSCM evaluation of a laptop manufacturer in Malaysia. Khodaverdi et al. (2013) proposed a fuzzy multi-criteria approach for evaluate green suppliers and fuzzy set theory was used to obtain a clear / concrete value due to the subjective perception of human beings. The fuzzy TOPSIS approach was proposed to create a general performance score and a model was applied with a numerical example. Likewise, (Gupta et al., 2017) proposed a fuzzy TOPSIS approach for supplier evaluation and ranking problem. Kannan et al. (2014) proposed the type-1 fuzzy TOPSIS method to select a green supplier to a Brazilian electronics company. In their studies, it evaluated 12 suppliers and four dominant criteria were determined according to the preferences of decision makers. These: the commitment of managers in GSCM; Reducing materials / components or energy, reuse, recycling or retrieval; Compliance with legal environmental requirements and product designs that prevent or reduce the use of toxic or hazardous substances.

Vahabzadeh et al. (2015) applied an isosceles trapezoid type-2 fuzzy VIKOR approach by utilizing the opinions of academicians and experts in the industry to evaluate reverse logistics in a green framework. The for the electronics industry in Thailand (Sirisawat and Kiatcharoenpol, 2018), it combined two methods in a fuzzy environment in order aim to list the things that hindered the application of reverse logistics. In the first step, fuzzy AHP was used to determine the weights, and fuzzy TOPSIS was used for final sorting. Santos et al. (2019) identified green criteria with 32 different expert opinions in order to select suppliers for the furniture industry and the results were evaluated with fuzzy TOPSIS method. According to the findings, the first three criteria for sustainable supplier selection are: the commitment of managers in GSCM, Eco-design and Environmental Management System.

The literature reviewed is summarized in Table 1. The results show that MCDM methods are preferred in supplier selection and evaluation studies and TOPSIS method is generally applied with one or integrated another method.

Table 1. Literature Review

\begin{tabular}{ll}
\hline Reference & Method \\
\hline (JharkhariaandShankar, 2007) & ANP \\
(Büyüközkan et al., 2008) & Fuzzy AHP andFuzzy TOPSİS \\
(Kannan et al., 2009) & Fuzzy TOPSİS \\
(Awasthi et al., 2010) & Fuzzy TOPSís
\end{tabular}

\begin{tabular}{ll} 
(Sun, 2010) & Fuzzy AHP andFuzzy TOPSIS \\
(Yiner et al., 2011) & ANP \\
(Büyüközkanand Çifçi, 2011) & Fuzzy ANP \\
(Uysal, 2012) & DEMATEL \\
(Büyüközkanand Çifçi, 2012) & FuzzyBased DEMATEL, ANP, TOPSí \\
(Khodaverdi et al., 2013) & Fuzzy TOPSis \\
(Jayant et al., 2014) & AHP-TOPSíS \\
(DobosandVörösmarty, 2014) & VZA \\
(Kannan et al., 2014) & Fuzzy TOPSis \\
(Rostamzadeh et al., 2015) & Fuzzy VIKOR \\
(Govindan et al., 2015) & Fuzzy DEMATEL \\
(Vahabzadeh et al., 2015) & Type-2 Fuzzy VIKOR \\
(Gupta et al., 2017) & Fuzzy TOPSís \\
(SirisawatandKiatcharoenpol, 2018) & Fuzzy AHP andFuzzy TOPSíS \\
(Santos et al., 2019) & Fuzzy TOPSis \\
\hline
\end{tabular}

\section{METHODOLOGY}

The methodological approach in the present study is discussed under two main headings. In the first step, interval type-2 fuzzy sets are explained than in the second step, Type-2 Fuzzy TOPSIS method is explained.

\subsection{Interval Type-2 Fuzzy Sets}

Type-1 fuzzy sets are two-dimensional Type-2 fuzzy sets are three-dimensional. The 3rd dimension in type-2 fuzzy sets provides additional degree of freedom that allows direct modeling of uncertainties, thus helping to eliminate further uncertainty (Ayvaz and Kuşakçı, 2017).

Definition 1. $\tilde{\tilde{A}}$ is a T2FS, $x \in X$ ve $u \in J_{x} \subseteq[0,1]$ a type-2 membership function expressed $\mu_{\tilde{A}}(x, u)$.

$\tilde{\tilde{A}}=\left\{\left((x, u), \mu_{\tilde{A}}(x, u)\right) \mid \forall x \in X, \forall u \in J_{x} \subseteq[0,1], 0 \leq\right.$ $\left.\mu_{\tilde{\tilde{A}}}(x, u) \leq 1\right\}$

$J_{x} \subseteq[0,1], \tilde{A}$ type-2 fuzzy set can also be shown as follows:

$$
\tilde{\tilde{A}}=\int_{x \in X} \int_{u \in J_{x}} \mu_{\tilde{A}}(x, u) /(x, u)
$$

Definition 2.The loweranduppermembershipfunctions of a type-2 intervalfuzzysetsare type-1 fuzzysets. In the universal set of $\mathrm{X}$, a interval type-2 fuzzy set $\tilde{\tilde{A}}$ is shown as follow: $\widetilde{\widetilde{A}}_{i}=\left(\tilde{A}_{i}^{U}, \tilde{A}_{i}^{L}\right)=$ $\left(a_{i 1}^{U}, a_{i 2}^{U}, a_{i 3}^{U}, a_{i 4}^{U} ; H_{1}\left(\tilde{A}_{i}^{U}\right), H_{2}\left(\tilde{A}_{i}^{U}\right)\right)$, 
24 C. Atasever, and B. Ayvaz / Southeast Europe Journal of Soft Computing Vol.8 No.2 September 2019 (21-30)

$$
\left(a_{i 1}^{L}, a_{i 2}^{L}, a_{i 3}^{L}, a_{i 4}^{L} ; H_{1}\left(\tilde{A}_{i}^{L}\right), H_{2}\left(\tilde{A}_{i}^{L}\right)\right)
$$

Where $H_{j}\left(\tilde{A}_{i}^{U}\right)$, denotes the membership value of the element $a_{i(j+1)}^{U}$ in the upper trapezoidal membership function $\tilde{A}_{i}^{U}\left(\tilde{A}_{i}^{U}, 1 \leq j \leq 2\right) . H_{j}\left(\tilde{A}_{i}^{L}\right)$, denotes the membership value of the element $a_{i(j+1)}^{L}$ in the lower trapezoidal membership function $\quad \tilde{A}_{i}^{L} \widetilde{A}_{i}^{L}, 1 \leq j \leq 2, H_{j}\left(\tilde{A}_{i}^{U}\right) \in[0,1], H_{1}\left(\tilde{A}_{i}^{L}\right) \in$ $[0,1], H_{2}\left(\tilde{A}_{i}^{L}\right) \in[0,1]$ and $1 \leq j \leq n$.

The graph of membership function for Type-2 fuzzy sets is shown in Figure 1 below. (Ayvaz and Kuşakçı, 2017)

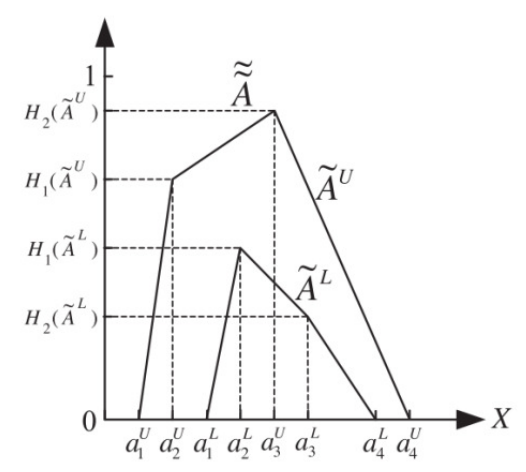

Figure 1. Type-2 Membership Function (Ayvaz and Kuşakçı, 2017)

3.1.1 The Arithmetic Operations Between The Trapezoid Interval Fuzzy Sets

$$
\begin{gathered}
\tilde{\tilde{A}}_{1}=\left(\tilde{A}_{1}^{U}, \tilde{A}_{1}^{L}\right)=\left(a_{11}^{U}, a_{12}^{U}, a_{13}^{U}, a_{14}^{U} ; H_{1}\left(\tilde{A}_{1}^{U}\right), H_{2}\left(\tilde{A}_{1}^{U}\right)\right), \\
\left(a_{11}^{L}, a_{12}^{L}, a_{13}^{L}, a_{14}^{L} ; H_{1}\left(\tilde{A}_{1}^{L}\right), H_{2}\left(\tilde{A}_{1}^{L}\right)\right) \\
\tilde{\tilde{A}}_{2}=\left(\tilde{A}_{2}^{U}, \tilde{A}_{2}^{L}\right)=\left(a_{21}^{U}, a_{22}^{U}, a_{23}^{U}, a_{24}^{U} ; H_{1}\left(\tilde{A}_{2}^{U}\right), H_{2}\left(\tilde{A}_{2}^{U}\right)\right), \\
\left(a_{21}^{L}, a_{22}^{L}, a_{23}^{L}, a_{24}^{L} ; H_{1}\left(\tilde{A}_{2}^{L}\right), H_{2}\left(\tilde{A}_{2}^{L}\right)\right)
\end{gathered}
$$

The Arithmeticoperationsbetween the trapezoidintervalfuzzysets $\widetilde{\widetilde{A}}_{1}$ and $\tilde{\tilde{A}}_{2}$ are defined as follows:

$$
\begin{aligned}
& \text { Definition } 3 . \\
& \qquad \tilde{\tilde{A}}_{1} \oplus \tilde{\tilde{A}}_{2}=\left(\tilde{A}_{1}^{U}, \tilde{A}_{1}^{L}\right) \oplus\left(\tilde{A}_{2}^{U}, \tilde{A}_{2}^{L}\right) \\
& =\left[a_{11}^{U}+a_{21}^{U}, a_{12}^{U}+a_{22}^{U}, a_{13}^{U}+a_{23}^{U}, a_{14}^{U}\right. \\
& \left.+a_{24}^{U} ; \min \left(H_{1}\left(\tilde{A}_{1}^{U}\right), H_{1}\left(\tilde{A}_{2}^{U}\right)\right), \min \left(H_{2}\left(\tilde{A}_{1}^{U}\right), H_{2}\left(\tilde{A}_{2}^{U}\right)\right)\right] \\
& \quad\left[\left(a_{11}^{L}+a_{21}^{L}, a_{12}^{L}+a_{22}^{L}, a_{13}^{L}+a_{23}^{L}, a_{14}^{L}\right.\right. \\
& \quad+a_{24}^{L} ; \min \left(H_{1}\left(\tilde{A}_{1}^{L}\right), H_{1}\left(\tilde{A}_{2}^{L}\right)\right), \min \left(H_{2}\left(\tilde{A}_{1}^{L}\right), H_{2}\left(\tilde{A}_{2}^{L}\right)\right)
\end{aligned}
$$

\section{Definition 4.}

$$
\begin{aligned}
& \tilde{\tilde{A}}_{1} \ominus \tilde{\tilde{A}}_{2}=\left(\tilde{A}_{1}^{U}, \tilde{A}_{1}^{L}\right) \ominus\left(\tilde{A}_{2}^{U}, \tilde{A}_{2}^{L}\right) \\
& =\left[a_{11}^{U}-a_{21}^{U}, a_{12}^{U}-a_{22}^{U}, a_{13}^{U}-a_{23}^{U}, a_{14}^{U}\right. \\
& \left.-a_{24}^{U} ; \min \left(H_{1}\left(\tilde{A}_{1}^{U}\right), H_{1}\left(\tilde{A}_{2}^{U}\right)\right), \min \left(H_{2}\left(\tilde{A}_{1}^{U}\right), H_{2}\left(\tilde{A}_{2}^{U}\right)\right)\right], \\
& {\left[a_{11}^{L}-a_{21}^{L}, a_{12}^{L}-a_{22}^{L}, a_{13}^{L}-a_{23}^{L}, a_{14}^{L}\right.} \\
& -a_{24}^{L} ; \min \left(H_{1}\left(\tilde{A}_{1}^{L}\right), H_{1}\left(\tilde{A}_{2}^{L}\right)\right), \min \left(H_{2}\left(\tilde{A}_{1}^{L}\right), H_{2}\left(\tilde{A}_{2}^{L}\right)\right)
\end{aligned}
$$

Definition 5.

$$
\begin{aligned}
& \tilde{\tilde{A}}_{1} \otimes \tilde{\tilde{A}}_{2}=\left(\tilde{A}_{1}^{U}, \tilde{A}_{1}^{L}\right) \otimes\left(\tilde{A}_{2}^{U}, \tilde{A}_{2}^{L}\right) \\
& =\left[a_{11}^{U} \times a_{21}^{U}, a_{12}^{U} \times a_{22}^{U}, a_{13}^{U} \times a_{23}^{U}, a_{14}^{U}\right. \\
& \left.\times a_{24}^{U} ; \min \left(H_{1}\left(\tilde{A}_{1}^{U}\right), H_{1}\left(\tilde{A}_{2}^{U}\right)\right), \min \left(H_{2}\left(\tilde{A}_{1}^{U}\right), H_{2}\left(\tilde{A}_{2}^{U}\right)\right)\right], \\
& {\left[a_{11}^{L} \times a_{21}^{L}, a_{12}^{L} \times a_{22}^{L}, a_{13}^{L} \times a_{23}^{L}, a_{14}^{L}\right.} \\
& \left.\times a_{24}^{L} ; \min \left(\mathrm{H}_{1}\left(\tilde{A}_{1}^{L}\right), H_{1}\left(\tilde{A}_{2}^{L}\right)\right), \min \left(\mathrm{H}_{2}\left(\tilde{A}_{1}^{L}\right), H_{2}\left(\tilde{A}_{2}^{L}\right)\right)\right]
\end{aligned}
$$

Definition 6.

$$
\begin{aligned}
& \tilde{\tilde{A}}_{1}=\left(\tilde{A}_{1}^{U}, \tilde{A}_{1}^{L}\right)=\left(a_{11}^{U}, a_{12}^{U}, a_{13}^{U}, a_{14}^{U} ; H_{1}\left(\tilde{A}_{1}^{U}\right), H_{2}\left(\tilde{A}_{1}^{U}\right)\right), \\
& \begin{aligned}
\left(a_{11}^{L}, a_{12}^{L}, a_{13}^{L}, a_{14}^{L} ;\right. & \left.H_{1}\left(\tilde{A}_{1}^{L}\right), H_{2}\left(\tilde{A}_{1}^{L}\right)\right) \\
k \tilde{A}_{1}=\left(k \times a_{11}^{U},\right. & k \times a_{12}^{U}, k \times a_{13}^{U}, k \\
& \left.\times a_{14}^{U} ; H_{1}\left(\tilde{A}_{1}^{U}\right), H_{2}\left(\tilde{A}_{1}^{U}\right)\right),\left[k \times a_{11}^{L}, k\right. \\
& \left.\times a_{12}^{L}, k \times a_{13}^{L}, k \times a_{14}^{L} ; H_{1}\left(\tilde{A}_{1}^{L}\right), H_{2}\left(\tilde{A}_{1}^{L}\right)\right]
\end{aligned} \\
& \begin{aligned}
\frac{\tilde{A}_{1}}{k}=\left(\frac{a_{11}^{U}}{k}, \frac{a_{12}^{U}}{k}, \frac{a_{13}^{U}}{k}, \frac{a_{14}^{U}}{k} ; H_{1}\left(\tilde{A}_{1}^{U}\right), H_{2}\left(\tilde{A}_{1}^{U}\right)\right), \\
\left(a_{11}^{L} / k, a_{12}^{L} / k, a_{13}^{L} / k, a_{14}^{L} / k ; H_{1}\left(\tilde{A}_{1}^{L}\right), H_{2}\left(\tilde{A}_{1}^{L}\right)\right)
\end{aligned}
\end{aligned}
$$

Definition 7.The ranking value $\operatorname{Rank}\left(\tilde{\tilde{A}}_{i}\right)$ of the trapezoidal interval T2FSs $\tilde{\tilde{A}}_{i}$ is defined as follows:

$$
\begin{aligned}
\operatorname{Rank}\left(\tilde{\tilde{A}}_{i}\right)=M_{1} & \left(\tilde{A}_{i}^{U}\right)+M_{1}\left(\tilde{A}_{i}^{L}\right)+M_{2}\left(\tilde{A}_{i}^{U}\right)+M_{2}\left(\tilde{A}_{i}^{L}\right) \\
& +M_{3}\left(\tilde{A}_{i}^{U}\right)+M_{3}\left(\tilde{A}_{i}^{L}\right) \\
& -\frac{1}{4}\left(S_{1}\left(\tilde{A}_{i}^{U}\right)+S_{1}\left(\tilde{A}_{i}^{L}\right)+S_{2}\left(\tilde{A}_{i}^{U}\right)\right. \\
& +S_{2}\left(\tilde{A}_{i}^{L}\right)+S_{3}\left(\tilde{A}_{i}^{U}\right)+S_{3}\left(\tilde{A}_{i}^{L}\right)+S_{4}\left(\tilde{A}_{i}^{U}\right) \\
& \left.+S_{4}\left(\tilde{A}_{i}^{L}\right)\right)+H_{1}\left(\tilde{A}_{i}^{U}\right)+H_{1}\left(\tilde{A}_{i}^{L}\right) \\
& +H_{2}\left(\tilde{A}_{i}^{U}\right)+H_{2}\left(\tilde{A}_{i}^{L}\right)
\end{aligned}
$$

Where $M_{p}\left(\tilde{A}_{i}^{j}\right)$, denotes the average of the elements $a_{i p}^{j}$ and $a_{i(p+1)}^{j}$,

$M_{p}\left(\tilde{A}_{i}^{j}\right)=\frac{\left(a_{i p}^{j}+a_{i(p+1)}^{j}\right)}{2}, 1 \leq p \leq 3$, denotes the standard deviation of the elements $a_{i p}^{j}$ and $a_{i(p+1)}^{j}, \quad S_{p}\left(\tilde{A}_{i}^{j}\right)=$ $\sqrt{\frac{1}{2} \sum_{k=q}^{q+1}\left(a_{i k}^{j}-\frac{1}{2} \sum_{k=q}^{q+1} a_{i k}^{j}\right)^{2}}, 1 \leq q \leq 3 \quad$ denotes the standard deviation of the elements $a_{i 1}^{j}, a_{i 2}^{j}, a_{i 3}^{j}, a_{i 4}^{j}$, 
25 C. Atasever, and B. Ayvaz / Southeast Europe Journal of Soft Computing Vol.8 No.2 September 2019 (21-30)

$S_{4}\left(\tilde{A}_{i}^{j}\right)=\sqrt{\frac{1}{4} \sum_{k=1}^{4}\left(a_{i k}^{j}-\frac{1}{4} \sum_{k=1}^{4} a_{i k}^{j}\right)^{2}} H_{p}\left(\tilde{A}_{i}^{j}\right)$ denotes the membership value of the element $a_{i(p+1)}^{j}$ in the trapezoidal membership function $\tilde{A}_{i}^{j}, 1 \leq p \leq 3, j \in\{U, L\}$, and $1 \leq i \leq$ $n$.

\subsection{Interval Type-2 Fuzzy TOPSis}

The TOPSIS method, which is based on proximity to positive ideal solution and distance to negative ideal solution, was developed in 1981 by Hwang and Yoon (Ayvaz and Kuşakçı, 2017).

In this study, it is aimed obtain real life-appropriate results so TOPSIS method is used in combination with fuzzy logic. It is assumed that there are $\mathrm{X}$ alternatives, where $\mathrm{X}=\left\{x_{1}, x_{2}, \ldots, x_{n}\right\}$ and $\mathrm{Y}$ criteria's, where $\mathrm{Y}=\left\{y_{1}, y_{2}, \ldots, y_{n}\right\}$. The set Yof criteria's can be divided into two sets $\left(Y_{1}\right.$ and $\left.Y_{2}\right)$. Where $Y_{1}$ denotes the set of benefit criteria and $Y_{2}$ denotes the set of cost criteria $Y_{1} \cap Y_{2}=\emptyset$ and $\mathrm{Y}_{1} \cup \mathrm{Y}_{2}=\mathrm{Y}$. There are $\mathrm{k}$ decision makers $D_{1}, D_{2}, \ldots$, and $D_{k}$. The details of the method are presented as follows:

Step 1: Using linguistic terms and trapezoidal interval type-2 fuzzy sets, the decision matrix that $\mathrm{k}$ decision makers will evaluate using these linguistic terms has been formed. Linguistic terms and fuzzy set equivalents are shown in Table 2 for criteria and Table 3 for alternatives.

Table 2.Linguistic Terms for Criteria and Their Corresponding İnterval Type-2 Fuzzy Sets

\begin{tabular}{ll}
\hline Linguistic Terms & Interval Type-2 Fuzzy Sets \\
\hline Very Low (VL) & $((0,0,0.1 ; 1,1),(0,0,0,0.05 ; 0.9,0.9))$ \\
Low (L) & $((0,0.1,0.1,0.3 ; 1,1),(0.05,0.1,0.1,0.2 ; 0.9,0.9))$ \\
Medium Low (ML) & $((0.1,0.3,0.3,0.5 ; 1,1),(0.2,0.3,0.3,0.4 ; 0.9,0.9))$ \\
Medium (M) & $((0.3,0.5,0.5,0.7 ; 1,1),(0.4,0.5,0.5,0.6 ; 0.9,0.9))$ \\
Medium High (MH) & $((0.5,0.7,0.7,0.9 ; 1,1),(0.6,0.7,0.7,0.8 ; 0.9,0.9))$ \\
High (H) & $((0.7,0.9,0.9,1 ; 1,1),(0.8,0.9,0.9,0.95 ; 0.9,0.9))$ \\
Very High (VH) & $((0.9,1,1,1 ; 1,1),(0.95,1,1,1 ; 0.9,0.9))$ \\
\hline
\end{tabular}

Table 3. Linguistic Terms for Alternatives and Their Corresponding İnterval Type-2 Fuzzy Sets

\begin{tabular}{ll}
\hline Linguistic Terms & Interval Type-2 Fuzzy Sets \\
\hline Very Poor (VP) & $((0,0,0.1 ; 1,1),(0,0,0,0.05 ; 0.9,0.9))$ \\
Poor (P) & $((0,0.1,0.1,0.3 ; 1,1),(0.05,0.1,0.1,0.2 ; 0.9,0.9))$ \\
Medium Poor (MP) & $((0.1,0.3,0.3,0.5 ; 1,1),(0.2,0.3,0.3,0.4 ; 0.9,0.9))$ \\
Medium (M) & $((0.3,0.5,0.5,0.7 ; 1,1),(0.4,0.5,0.5,0.6 ; 0.9,0.9))$ \\
Medium Good (MG) & $((0.5,0.7,0.7,0.9 ; 1,1),(0.6,0.7,0.7,0.8 ; 0.9,0.9))$ \\
Good (G) & $((0.7,0.9,0.9,1 ; 1,1),(0.8,0.9,0.9,0.95 ; 0.9,0.9))$ \\
Very Good (VG) & $((0.9,1,1,1 ; 1,1),(0.95,1,1,1 ; 0.9,0.9))$ \\
\hline
\end{tabular}

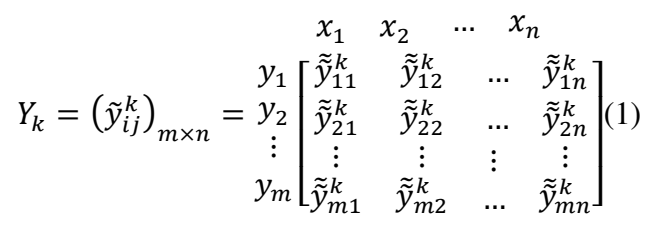

$\overline{\mathrm{Y}}=\left(\tilde{y}_{i j}\right)_{m \times n}$

where $\tilde{y}_{i j}=\left(\frac{\tilde{y}_{i j}^{1} \otimes \tilde{y}_{i j}^{2} \otimes \tilde{y}_{i j}^{3} \otimes \tilde{y}_{i j}^{4}}{k}\right), \tilde{y}_{i j}$ is an interval type-2 fuzzy set, $1 \leq i \leq m, 1 \leq j \leq n, 1 \leq p \leq k$ and $\mathrm{k}$ denotes the number of decision-makers.

Step 2: The calculation the weighting matrix $\mathrm{Wk}$ of the criteria of the kth decision makers and find the average weighting matrix $\overline{\mathrm{W}}$ :

$$
\begin{aligned}
& \left.W_{k=}\left(\widetilde{\widetilde{w}}_{i}^{k}\right)_{1 \times n}=\begin{array}{cccc}
y_{1} & y_{2} & \ldots & y_{n} \\
\widetilde{\widetilde{w}}_{1}^{k} & \widetilde{\widetilde{w}}_{2}^{k} & \ldots & \widetilde{\widetilde{w}}_{m}^{k}
\end{array}\right] \\
& \overline{\mathrm{W}}=\left(\widetilde{\widetilde{w}}_{i}\right)_{1 \times m}
\end{aligned}
$$

Where $\widetilde{\widetilde{w}}=\left(\frac{\widetilde{w}_{i}^{1} \otimes \widetilde{w}_{i}^{2} \otimes \widetilde{w}_{i}^{3} \otimes \widetilde{w}_{i}^{4}}{k}\right), \widetilde{\widetilde{w}}_{i}$ is an interval type-2 fuzzy set, $1 \leq i \leq m, 1 \leq j \leq n, 1 \leq p \leq k$ and $\mathrm{k}$ denotes the number of decision-makers.

Step 3: Calculation the weighted decision matrix $\overline{\mathrm{Y}}_{w}$ :

$$
\begin{aligned}
& \begin{array}{llll}
x_{1} & x_{2} & \ldots & x_{n}
\end{array}
\end{aligned}
$$

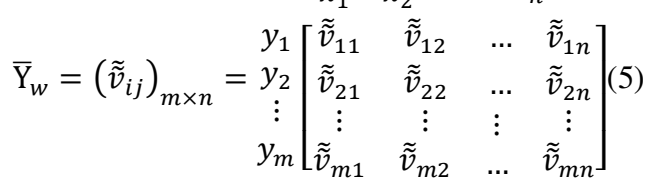

Step 4: Calculate the ranking value $\operatorname{Rank}\left(\tilde{\tilde{v}}_{i j}\right)$ of the interval type-2 fuzzy set $\tilde{\tilde{v}}_{i j}$ where $1 \leq j \leq n$. Obtain the ranking weighted decision matrix $\bar{Y}_{w}^{*}$ :

$$
\begin{aligned}
& \operatorname{Rank}\left(\tilde{\tilde{A}}_{i}\right)=M_{1}\left(\tilde{A}_{i}^{U}\right)+M_{1}\left(\tilde{A}_{i}^{L}\right)+M_{2}\left(\tilde{A}_{i}^{U}\right)+M_{2}\left(\tilde{A}_{i}^{L}\right)+ \\
& M_{3}\left(\tilde{A}_{i}^{U}\right)+M_{3}\left(\tilde{A}_{i}^{L}\right)-\frac{1}{4}\left(S_{1}\left(\tilde{A}_{i}^{U}\right)+S_{1}\left(\tilde{A}_{i}^{L}\right)+S_{2}\left(\tilde{A}_{i}^{U}\right)+\right. \\
& \left.S_{2}\left(\tilde{A}_{i}^{L}\right)+S_{3}\left(\tilde{A}_{i}^{U}\right)+S_{3}\left(\tilde{A}_{i}^{L}\right)+S_{4}\left(\tilde{A}_{i}^{U}\right)+S_{4}\left(\tilde{A}_{i}^{L}\right)\right)+ \\
& H_{1}\left(\tilde{A}_{i}^{U}\right)+H_{1}\left(\tilde{A}_{i}^{L}\right)+H_{2}\left(\tilde{A}_{i}^{U}\right)+H_{2}\left(\tilde{A}_{i}^{L}\right)(6) \\
& \bar{Y}_{w}^{*}=\operatorname{Rank}\left(\tilde{\tilde{v}}_{i j}\right)_{m \times n} \\
& 1 \leq i \leq m, 1 \leq j \leq n .
\end{aligned}
$$

Step 5: Find the Positive ideal solition $x^{+}=\left(v_{1}^{+}, v_{1}^{+}, \ldots ., v_{m}^{+}\right)$and the negatife ideal solition $x^{-}=\left(v_{1}^{-}, v_{1}^{-}, \ldots ., v_{m}^{-}\right)$. Where $Y_{1}$ denotes the set of benefit criteria, $Y_{2}$ denotes the set of cost criteriaand $1 \leq i \leq m$.

$$
v_{i}^{+}=\left\{\begin{array}{l}
\max \left\{\operatorname{Rank}\left(\tilde{\tilde{v}}_{i j}\right), \text { if } y_{i} \in Y_{1}\right. \\
\min \left\{\operatorname{Rank}\left(\tilde{\tilde{v}}_{i j}\right), \text { if } y_{i} \in Y_{2}\right.
\end{array} 1 \leq j\right.
$$


and

$v_{i}^{-}=\left\{\begin{array}{l}\min \left\{\operatorname{Rank}\left(\tilde{\tilde{v}}_{i j}\right), \text { if } y_{i} \in Y_{1}\right. \\ \max \left\{\operatorname{Rank}\left(\tilde{\tilde{v}}_{i j}\right), \text { if } y_{i} \in Y_{2}\right.\end{array} 1 \leq j \leq n\right.$

Step 6: Using the following equations, the relative proximity index $C\left(x_{j}\right)$ is calculated by finding the distances to the positive ideal solution and the negative ideal solution:

$d^{+}\left(x_{j}\right)=\sqrt{\sum_{i: 1}^{m}\left(\operatorname{Rank}\left(\tilde{\tilde{v}}_{i j}\right)-v_{i}^{+}\right)^{2}}$,

$d^{-}\left(x_{j}\right)=\sqrt{\sum_{i: 1}^{m}\left(\operatorname{Rank}\left(\tilde{\tilde{v}}_{i j}\right)-v_{i}^{-}\right)^{2}}$,

$C\left(x_{j}\right)=\frac{d^{-}\left(x_{j}\right)}{d^{+}\left(x_{j}\right)+d^{-}\left(x_{j}\right)}$

Step 7: In the last step, the $\mathrm{C}\left(\mathrm{x}_{\mathrm{j}}\right)$ closeness scores are sorted from large to small. This ranking refers to the order of alternatives from the best to the lowest according to their green performance.

\section{APPLICATION}

The proposed method was applied to assess the green performance of $3 \mathrm{PL}$ providers operating in the logistics sector. There are 3 alternative firms for performance evaluation $A_{i}(i=1,2,3)$, Three decision-makers to determine the significance of the criteria and evaluate alternatives $\mathrm{DM}_{\mathrm{k}}(\mathrm{k}=1,2,3)$ and 11 criteria for evaluating firm performance. C1: Environmental Design (Awasthi et al., 2010; Govindan et al., 2017; Kannan et al., 2014; Khodaverdi et al., 2013; Laari et al., 2016; Sari, 2017), C2: Environment-Friendly Technology and R\&D (Gupta et al., 2017; Uygun and Dede, 2016), C3: Green Purchasing (Awasthi et al., 2010; Erol et al., 2011; Helmi et al., 2015), C4: Eco-Friendly Packaging (Chhabra et al., 2017), C5: Green / Eco Logistics (Kannan et al., 2014; Sari, 2017; Uygun and Dede, 2016), C6: Reverse Logistics (Govindan et al., 2015; Laari et al., 2016; Yiner et al., 2011), C7: EcoFriendly Storage (Gupta et al., 2017; Rostamzadeh et al., 2015), C8: Green Management (Cullinane and Rashidi, 2019), C9: Cooperation for the Environment (Chang et al., 2018), C10: Environmental Education (Awasthi et al., 2010; Khodaverdi et al., 2013), C11: Waste Management and Air Emission (Chang et al., 2018; Saen et al., 2014). These criteria are shown in Figure 2 below.

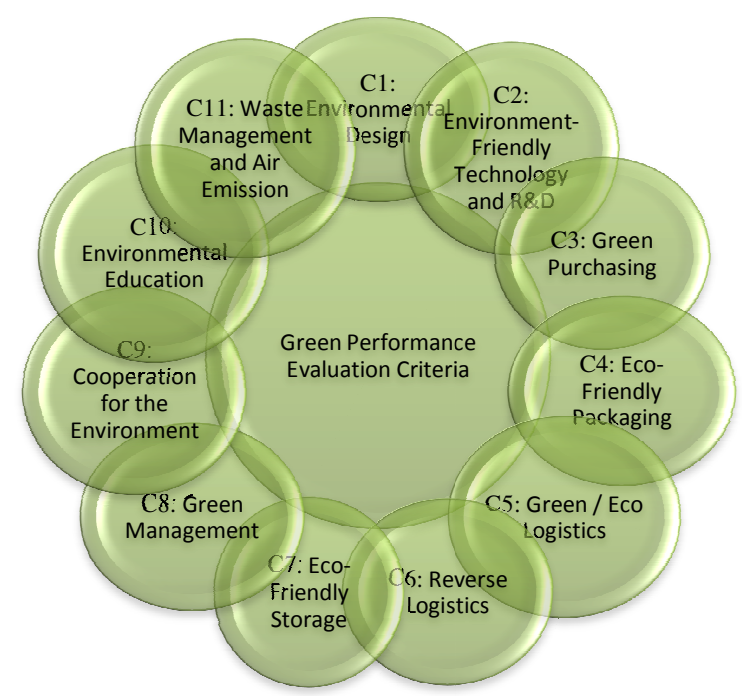

Figure 2. Green Performance Evaluation Criteria

\section{1 İnterval Type-2 Fuzzy TOPSIS Solutions:}

In the first step, decision-makers (DM1, DM2, DM3) determine the level of importance of the 11 criteria for the green performance assessment study using the linguistic terms given in Table 2. The linguistic responses given by the decision-makers for the significance levels of the criterion for the green performance evaluation study using Table 2 are given in Table 4 and interval type-2 fuzzy numbers corresponding of the average criterion weights are given in Table 5 .

Table 4. Linguistic Weights Given to Criteria by DecisionMakers

\begin{tabular}{lccc}
\hline Decision-Makers & DM1 & DM2 & DM3 \\
\hline Criteria & \multicolumn{3}{c}{ Linguistic Weights } \\
\hline C1 & VH & H & VH \\
C2 & H & MH & VH \\
C3 & H & H & VH \\
C4 & L & L & VH \\
C5 & VH & H & VH \\
C6 & H & H & MH \\
C7 & H & H & VH \\
C8 & H & H & VH \\
C9 & MH & M & VH \\
C10 & H & H & VH \\
C11 & VH & H & VH \\
\hline
\end{tabular}


27 C. Atasever, and B. Ayvaz / Southeast Europe Journal of Soft Computing Vol.8 No.2 September 2019 (21-30)

Table 5. Type-2 FuzzyWeights of Evaluation Criteria

$$
\begin{array}{cc}
\widetilde{\widetilde{w}}_{1} & ((0.83,0.97,0.97,1.00,1.00,1.00),(0.90,0.97,0.97,0.98,0.90,0.90)) \\
\widetilde{w}_{2} & ((0.70,0.87,0.87,0.97,1.00,1.00),(0.78,0.87,0.87,0.92,0.90,0.90)) \\
\widetilde{\widetilde{w}}_{3} & ((0.77,0.93,0.93,1.00,1.00,1.00),(0.85,0.93,0.93,0.97,0.90,0.90)) \\
\widetilde{w}_{4} & ((0.30,0.40,0.40,0.53,1.00,1.00),(0.35,0.40,0.40,0.47,0.90,0.90)) \\
\widetilde{w}_{5} & ((0.83,0.97,0.97,1.00,1.00,1.00),(0.90,0.97,0.97,0.98,0.90,0.90)) \\
\widetilde{w}_{6} & ((0.63,0.83,0.83,0.97,1.00,1.00),(0.73,0.83,0.83,0.90,0.90,0.90)) \\
\widetilde{w}_{7} & ((0.77,0.93,0.93,1.00,1.00,1.00),(0.85,0.93,0.93,0.97,0.90,0.90)) \\
\widetilde{w}_{8} & ((0.77,0.93,0.93,1.00,1.00,1.00),(0.85,0.93,0.93,0.97,0.90,0.90)) \\
\widetilde{w}_{9} & ((0.57,0.73,0.73,0.87,1.00,1.00),(0.65,0.73,0.73,0.80,0.90,0.90)) \\
\widetilde{w}_{10} & ((0.77,0.93,0.93,1.00,1.00,1.00),(0.85,0.93,0.93,0.97,0.90,0.90)) \\
\widetilde{w}_{11} & ((0.83,0.97,0.97,1.00,1.00,1.00),(0.90,0.97,0.97,0.98,0.90,0.90)) \\
\hline
\end{array}
$$

In the second step, the decision makers (DM1, DM2, DM3) asses to alternatives (S1, S2, S3) according to the green performance evaluation criteria $(\mathrm{C} 1, \mathrm{C} 2, \mathrm{C} 3, \mathrm{C} 4, \mathrm{C} 5, \mathrm{C} 6$, $\mathrm{C} 7, \mathrm{C} 8, \mathrm{C} 9, \mathrm{C} 10, \mathrm{C} 11)$ through in using the linguistic terms in Table 3. This assessment expressed as the degree to which alternatives meet the criteria. The linguistic assessment responses of the decision makers are given in Table 6.

Table 6. LinguisticAssessmentResponses of The DecisionMakers

\begin{tabular}{cccccccccc}
\hline & \multicolumn{3}{c}{ DM1 } & \multicolumn{3}{c}{ DM2 } & \multicolumn{3}{c}{ DM3 } \\
\hline & S1 & S2 & S3 & S1 & S2 & S3 & S1 & S2 & S3 \\
\hline C1 & G & M & M & MG & M & M & G & G & M \\
C2 & VG & MP & MG & VG & M & MG & VG & G & MG \\
C3 & MG & MG & M & VG & MG & M & G & MG & M \\
C4 & MG & M & MG & G & MG & MG & MG & G & MG \\
C5 & VG & G & M & VG & MG & M & VG & G & M \\
C6 & G & M & MG & G & G & MG & G & G & MG \\
C7 & VG & G & MG & G & G & MG & G & G & MG \\
C8 & G & G & MG & VG & G & MG & VG & G & MG \\
C9 & VG & MG & M & G & MG & M & VG & G & M \\
C10 & P & G & P & VG & G & P & M & G & MP \\
C11 & VP & MG & M & VG & MG & M & M & MG & M \\
\hline
\end{tabular}

In the next step, the weighted interval type-2 fuzzy evaluation matrix is obtained using Eqs. (3-5). Then using Eqs. (6-7) the ranks $\operatorname{Rank}\left(\tilde{\tilde{v}}_{i j}\right)$ for alternatives is obtained shown in Table 7.
Table 7. The Ranksfor The Alternatives

\begin{tabular}{cccc}
\hline & S1 & S2 & S3 \\
\hline C1 & 8,22 & 7,10 & 6,36 \\
C2 & 8,60 & 6,40 & 7,09 \\
C3 & 8,24 & 7,35 & 6,26 \\
C4 & 5,39 & 5,23 & 5,24 \\
C5 & 9,20 & 8,22 & 6,36 \\
C6 & 7,88 & 7,24 & 6,95 \\
C7 & 8,59 & 8,40 & 7,35 \\
C8 & 8,79 & 8,40 & 7,35 \\
C9 & 7,68 & 6,83 & 5,70 \\
C10 & 6,47 & 8,40 & 4,50 \\
C11 & 6,41 & 7,49 & 6,36 \\
\hline
\end{tabular}

Then using Table 7 and Eqs. (8-9) the ranks for the positive ideal and negative ideal solutions are determined presented in Table 8.

Table 8. The PositiveIdealandNegativeIdeal Solutions

\begin{tabular}{cccccccccccc}
\hline & $\mathrm{C} 1$ & $\mathrm{C} 2$ & $\mathrm{C} 3$ & $\mathrm{C} 4$ & $\mathrm{C} 5$ & $\mathrm{C} 6$ & $\mathrm{C} 7$ & $\mathrm{C} 8$ & $\mathrm{C} 9$ & $\mathrm{C} 10$ & $\mathrm{C} 11$ \\
\hline $\begin{array}{c}(+) \\
\text { Ideal }\end{array}$ & 8,2 & 8,6 & 8,2 & 5,4 & 9,2 & 7,9 & 8,6 & 8,8 & 7,7 & 8,4 & 7,5 \\
$\begin{array}{c}(-) \\
\text { İdeal }\end{array}$ & 6,4 & 6,4 & 6,3 & 5,2 & 6,4 & 7,0 & 7,4 & 7,4 & 5,7 & 4,5 & 6,4 \\
\hline
\end{tabular}

Using Eqs. (10-11), it is obtained the distances from the positive ideal and negative ideal solutions presented in Table 9.

Table 9. Distancesfrom The PositiveIdealandNegativeIdeal Solutions

\begin{tabular}{lccc}
\hline & S1 & S2 & S3 \\
\hline d+ & 2,21 & 3,03 & 6,53 \\
d- & 5,71 & 5,02 & 0,69 \\
\hline
\end{tabular}

Finally, using Eqs. (12), the closeness index and the rankings results are obtained as can be seen in Table 10 .

Table 10. The Closeness Index and The Rankings

\begin{tabular}{lccc}
\hline & S1 & S2 & S3 \\
\hline C* & 0,72 & 0,62 & 0,10 \\
Ranking & 1 & 2 & 3 \\
\hline
\end{tabular}

According to Table 10, S1 is the 3PL provider that best meets the specified criteria for green performance. The performance ranking is $\mathrm{S} 1>\mathrm{S} 2>\mathrm{S} 3$. 


\subsection{Sensitivity Analyses}

In this section sensitivity analyses is conducted for type-2 fuzzy TOPSIS method in order to observe changing results with respect to the different weight of criteria. The criteria weights used for sensitivity analysis are shown in Table 11 for 11 different cases.

Table 11. Importance Weights of Criteria for Different Cases

\begin{tabular}{lccccccccccc}
\hline & C1 & C2 & C3 & C4 & C5 & C6 & C7 & C8 & C9 & C10 & C11 \\
\hline Case1 & M & M & M & M & M & M & M & M & M & M & M \\
Case2 & VH & VH & M & M & M & M & M & M & M & M & M \\
Case3 & VH & VH & VH & M & M & M & M & M & M & M & M \\
Case4 & VH & VH & VH & VH & M & M & M & M & M & M & M \\
Case5 & VH & VH & VH & VH & VH & M & M & M & M & M & M \\
Case6 & VH & VH & VH & VH & VH & VH & M & M & M & M & M \\
Case7 & VH & VH & VH & VH & VH & VH & VH & M & M & M & M \\
Case8 & VH & VH & VH & VH & VH & VH & VH & VH & M & M & M \\
Case9 & VH & VH & VH & VH & VH & VH & VH & VH & VH & M & M \\
Case10 & VH & VH & VH & VH & VH & VH & VH & VH & VH & VH & M \\
Case11 & VH & VH & VH & VH & VH & VH & VH & VH & VH & VH & VH \\
\hline
\end{tabular}

The Eqs. (3-12) are applied by changing weights for different cases. The closeness index $\left(\mathrm{C}^{*}\right)$ results for 11 different cases are shown in Table 12.

Table 12. The Closeness Index ( $\left.\mathrm{C}^{*}\right)$ for Different Cases

\begin{tabular}{lccc}
\hline & S1 & S2 & S3 \\
\hline Current Solution & 0,721 & 0,624 & 0,095 \\
Case 1 & 0,726 & 0,614 & 0,101 \\
Case 2 & 0,782 & 0,479 & 0,160 \\
Case 3 & 0,797 & 0,485 & 0,148 \\
Case 4 & 0,798 & 0,484 & 0,148 \\
Case 5 & 0,819 & 0,510 & 0,132 \\
Case 6 & 0,822 & 0,506 & 0,130 \\
Case 7 & 0,825 & 0,515 & 0,127 \\
Case 8 & 0,829 & 0,523 & 0,124 \\
Case 9 & 0,841 & 0,528 & 0,115 \\
Case 10 & 0,749 & 0,605 & 0,100 \\
Case 11 & 0,732 & 0,609 & 0,099 \\
\hline
\end{tabular}

According to the sensitivity analyses as be seen in Fig. 3 Changes in criterion weights did not lead to a change in ranking among 3PL providers, however differences in closeness index between alternatives based on criterion weights increased or decreased. Sensitivity analysis results show that the level of satisfying the criteria of the alternatives may vary depending on the criteria weights, and the performance difference between the alternatives may increase or decrease. Therefore, accurate determination of criteria's weights is of great importance for performance evaluation.

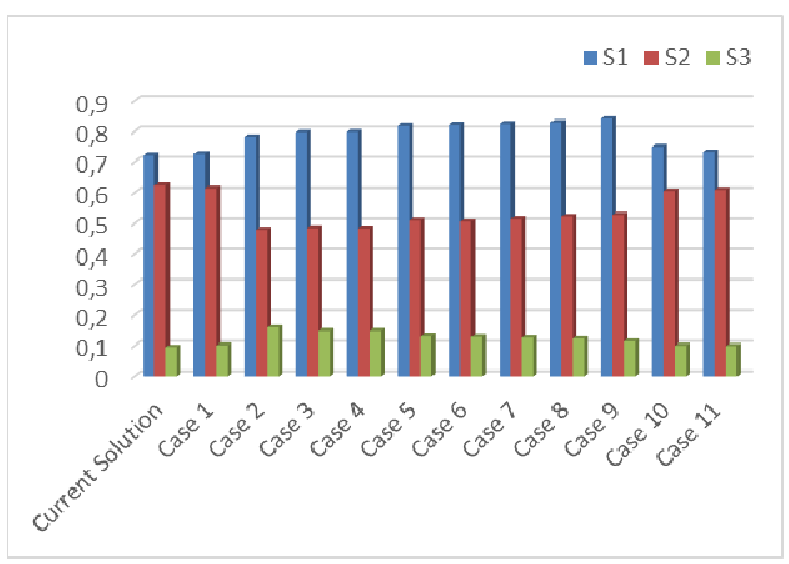

Figure 3. Sensitivity Analysis

\section{CONCLUSIONS}

The recent years, the concept of Supply Chain Management has been seen as a way of providing competitive advantage for companies and the selection of suppliers in accordance with the company criteria has been considered as a strategic advantage on this way. With the increasing sensitivity to the environment and the concern to leave enough resources for future generations, environmental dimensions have been included in all areas of life and every activity. These strategic way and strategic decisions have also gained an environmental dimension under the name of Green Supply Chain Management and green supplier selection and have received great interest in both academic and corporate life.

When the studies are examined, it is generally focused on the selection of green suppliers and the performance evaluation studies are quite few in contrast. A company's environmental performance depends on its internal efforts as well as on the environmental performance of its suppliers so the evaluation and improvement of the suppliers' performance is of great importance in order to improve their own performance.

This study is presented a method that can evaluate the green performances of the firms offering service 3PL. As with supplier selection, performance evaluation is multidimensional therefore, TOPSIS, one of the MCDM 
methods was used and because the linguistic preferences are utilized the method is combined with the fuzzy sets. The have seen that type- 2 fuzzy sets give better results than type1 fuzzy sets at the studies. Therefore, the interval type- 2 fuzzy TOPSIS method was used in this study for evaluate of green performance and three 3PL providers' green performances are evaluated.

In this study, green performance of three 3PL providers were evaluated under 11 criteria (Environmental Design, Environment-Friendly Technology and R\&D, Green Purchasing, Eco-Friendly Packaging, Green/Eco Logistics, Reverse Logistics, Eco-Friendly Storage, Cooperation for the Environment, Environmental Education, Waste Management and Air Emission) and it have been seen that the company with the best proximity index and best performance was $\mathrm{S} 1$. Then Sensitivity analysis was made for 11 different cases to see how criteria weights affect the result and have been seen criterion weights affect the difference in closeness index between alternatives.

As future studies, the proposed method can be applied to measure the performance of the current supplier in different periods and performance improvement studies can be carried out accordingly. In addition to the green performance evaluation work, the proposed method can be used in the selection and evaluation work to be done at every step of the decision-making process. The other MCDM methods such as AHP, ANP under type-2 fuzzy sets for criterion weighting can be combined with the proposed method and a binary approach can be obtained. Additionally, the other MCDM methods such as VIKOR, ELECTRE under the interval type- 2 fuzzy sets can be used for decision making and evaluation studies.

This study was produced from my thesis titled "YEŞIL PERFORMANS DEĞERLENDIRME ICCIN BULANIK TABANLI YENI BIR MODEL ÖNERISI'" which I am continuing in The Industrial Engineering Master Program of Istanbul Commerce University Institute of Science.

\section{REFERENCES}

Awasthi, A., Chauhan, S.S., Goyal, S.K., (2010), “A fuzzy multicriteria approach for evaluating environmental performance of suppliers", Int. J.ProductionEconomics, 126, 70-378.

Ayvaz, B., Kuşakçı, A.O., (2017), “A trapezoidal type-2 fuzzy multi-criteria decision making method based on TOPSIS for supplier selection: An application in textile sector", PamukkaleUnivMuhBilimDerg, 23, 70-79.

Banaeian, N., Mobli, H., Omid, M., Fahimnia, B., Nielsen, C., (2018), "Green supplier selection using fuzzy group decision making methods: A case study from the agri-food industry", Computers and Operations Research, 89, 337 347

Boyacı, A. İ., Çolak, M., (2018), “A Fuzzy Logic Based Green Performance Evaluation Model for Automotive Industry", European Journal of Science and Technology, 13, $39-44$.

Büyüközkan, G., Feyzioğlu, O., Nebol, E., (2008), "Selection of the strategic alliance partner in logistics value chain”, Int. J. Production Economics, 113, 148-158.

Büyüközkan, G., Çifçi, G., (2011), “A novel fuzzy multicriteria decision framework for sustainable supplier selection with incomplete information", Computers in Industry, 62, 164-174.

Büyüközkan, G., Çifçi, G., (2012), “A novel hybrid MCDM approach based on fuzzy DEMATEL, fuzzy ANP and fuzzy TOPSIS to evaluate green suppliers", Expert Systems with Applications, 39, 3000-3011.

Chang, Y., Zhang, J., Wang, C., Zhang, L., (2018), "The green efficiency of industrial sectors in China: A comparative analysis based on sectoral and supply-chain quantifications", Resources, Conservation and Recycling, $132,269-277$.

Chhabra, D., Garg, S. K., Singh, R. K., (2017), “Analyzing alternatives for green logistics in an Indian automotive organization: A case study", Journal of Cleaner Production, 167, 962-969.

Cullinane, K., Rashidi, K., (2019), “A comparison of fuzzy DEA and fuzzy TOPSIS in sustainable supplier selection: Implications for sourcing strategy", Expert Systems with Applications, 121, 266-281.

Dobos, I., Vörösmarty, G., (2014), "Green supplier selection and evaluation using DEA-type composite indicators", Int. J. Production Economics, 157, 273-278.

Erol, İ., Sencer, S., Sari, R., (2011), “A new fuzzy multicriteria framework for measuring sustainability performance of a supply chain”, Ecological Economics, 70, 1088-1100.

Govindan, K., Kadziński, M., Sivakumar, R., (2017), "Application of a novel PROMETHEE-based method for construction of a group compromise ranking to prioritization of green suppliers in food supply chain”, Omega, 71, 129145 .

Govindan, K., Khodaverdi, R., Vafadarnikjoo, A., (2015), "Intuitionistic fuzzy based DEMATEL method for developing green practices and performances in a green supply chain”, Expert Systems with Applications, 42, 72077220 .

Gupta, H., Barua, M. K., PhD, (2017), "Supplier selection among SMEs on the basis of their green innovation ability 
30 C. Atasever, and B. Ayvaz / Southeast Europe Journal of Soft Computing Vol.8 No.2 September 2019 (21-30)

using BWM and fuzzy TOPSIS", Journal of Cleaner Production, 152, 242-258.

Helmi, S. A., Galankashi, M. R., Chegeni, A., Soleimanynanadegany, A., Memari, A., Anjomshoae, A., Dargi, A., (2015), "Prioritizing Green Supplier Selection Criteria using Fuzzy Analytical Network Process", Procedia CIRP, 26, $689-694$.

Jayant, A., Gupta, P., Garg, S.K., Khan, M., (2014), "TOPSIS-AHP Based Approach for Selection of Reverse Logistics Service Provider: A Case Study of Mobile Phone Industry", Procedia Engineering, 97, 2147-2156.

Jharkharia, S., Shankar, R., (2007), "Selection of logistics service provider: An analytic network process (ANP) approach",Omega, 35, 274-289.

Kannan, D., Jabbour, A. B. L. S., Jabbour, C. J. C., (2014), "Selecting green suppliers based on GSCM practices: Using fuzzy TOPSIS applied to a Brazilian electronics company", European Journal of Operational Research, 233, 432-447.

Kannan, G., Pokharel, S., Kumar, P. S., (2009), "A hybrid approach using ISM and fuzzy TOPSIS for the selection of reverse logistics provider", Resources, Conservation and Recycling, 54, 28-36.

Khodaverdi, R.,Olfat, L., Govindan, K., Shen, L., Diabat, A., (2013), "A fuzzy multi criteria approach for evaluating green supplier's performance in green supply chain with linguistic preferences", Resources, Conservation and Recycling, 74, 170-179.

Laari, S., Töyli, J., Solakivi, T., Ojala, L., (2016), "Firm performance and customer-driven green supply chain management", Journal of Cleaner Production, 112,19601970.

Rostamzadeh, R., Govindan, K., Esmaeili, A., Sabaghi, M., (2015), "Application of fuzzy VIKOR for evaluation of green supply chain management practices", Ecological Indicators, 49, 188-203.

Saen, R. F., Azadi, M., Shabani, A., Khodakarami, M., (2014), "Planning in feasible region by two-stage targetsetting DEA methods: An application in green supply chain management of public transportation service providers", Transportation Research Part E, 70, 324-338.

Santos, B. M., Godoy, L. P., Campos, L. M. S., (2019), "Performance evaluation of green suppliers using entropyTOPSIS-F”, Journal of Cleaner Production, 207, 498-509.

Sari, K., (2017), "A novel multi-criteria decision framework for evaluating green supply chain management practices", Computers \& Industrial Engineering, 105, 338-347.

Sirisawat, P., Kiatcharoenpol, T., (2018), "Fuzzy AHPTOPSIS approaches to prioritizing solutions for reverse logistics barriers", Computers \& Industrial Engineering, 117, 303-318.

Sun, C., (2010), "A performance evaluation model by integrating fuzzy AHP and fuzzy TOPSIS methods", Expert Systems with Applications, 37, 7745-7754.

Uygun, Ö., Dede, A., (2016), "Performance evaluation of green supply chain management using integrated fuzzy multi-criteria decision making techniques", Computers \& Industrial Engineering, 102, 502-511.

Uysal, F., (2012), "An integrated model for sustainable performance measurement in supply chain", Procedia Social and Behavioral Sciences, 62, 689-694.

Vahabzadeh, A.H., Asiaei, A., Zailani, S., (2015), "Reprint of "Green decision-making model in reverse logistics using FUZZY-VIKOR method"”, Resources, Conservation and Recycling, 104, 334-347.

Yiner, L., Xuhong, Y., Jian, C., Yu, Q., (2011), "An Integrative Decision-making Model for the Operation of Sustainable Supply Chain in China", Energy Procedia, 5, 1497-1501. 